\title{
ABSTRACT \\ Activating Imaginative Attention and Creating Observant Moments in the Everyday Through the Art of Walking
}

Since 2013, I have been conducting a collaborative project on walking together with the actress and tightrope walker Helena Kågemark, where walking has become a means for inquiry-based performing. The purpose of this project was to apply techniques and strategies from the theatre work we pursue in situations outside of the theatre on walking actions in urban spaces - in order to create attention as well as bring forth poetry in situations of everyday life.

The project included a wide range of activities and events; from our own explorative walks documented through "walking journals" to participatory walks with others and public presentations of performance acts, performance lectures, discussions, workshops and exhibitions.

In our project, we used physical acting techniques to create attention and meaning in situations that emerged in the streets. Our aim was to go beyond the automatic patterns of the everyday when walking through town in order to activate a way to relate to the environment and to create experience that develops both

the perception and imagination of the one who walks. We chose to focus on the seemingly small and invisible stories and observations of the everyday, while actively carrying out a psychophysical walk.

In this article, I would like to reflect on certain parts of the walking project in

order to investigate more closely how we transferred our experience as theatre practitioners to walking activities, and in doing so, activating imaginative attention in order to create observant moments in everyday situations.

Keywords: walking, physical theatre, imaginative attention, everyday poetry, listening, performative writing, artistic research.

BIOGRAPHY

Cecilia Lagerström is a director, researcher and professor at the Academy of Music and Drama, University of Gothenburg in Sweden. She has a background in laboratory theatre and performance studies ( $\mathrm{PhD} 2003$ ), and has been directing performance work and artistic research and development projects for many years. Since 2005, Lagerström has been active in the development of artistic research in the field of the theatre in Sweden and is responsible for research in the dramatic arts at the academy. She is also regularly commissioned as a lecturer, opponent, committee member and adviser in artistic research contexts in different Nordic countries. cecilia.lagerstrom@hsm.gu.se 


\section{Activating Imaginative Attention and Creating Observant Moments in the Everyday Through the Art of Walking}

\section{CECILIA LAGERSTRÖM}

\section{INTRODUCTION}

Since 2013, I have been conducting a collaborative project on walking together with my working partner, the actress and tightrope walker Helena Kågemark, where walking has become a means for inquiry-based performing.

We have been pursuing theatre work and research-related projects within an improvisation-based and corporeal art form for many years now. In this walking project, we wanted to try out the mobile and associative approach characteristic of our theatre practice in other forums than the theatre. The purpose of this project was therefore to apply techniques and strategies from the theatre work we pursue in situations outside of the theatre on walking actions in urban spaces - in order to create attention as well as bring forth poetry in situations of everyday life. Our general aims included: the creating of work in public spaces that was neither announced nor commissioned, engaging with spectators in different ways, and reaching a wider audience than those who normally go to the theatre. These aims originated in a strong wish on our part to enter new areas, thus reaching beyond our usual local cultural sphere and creating other relationships with the audience than as consumers of culture. Above all, we wanted to investigate what it means to apply "walking strategies" in order to perceive and encounter one's surroundings, asking such questions as: how can we attain presence and create sites in our daily lives through the way we act, perceive and respond to our environment?

Exploring the art of walking implies entering different areas, such as performance art, visual art, city planning, sociology, activism, architecture, and art in public spaces. This project has not only taken us out of theatrical institutions into the streets, but even further afield into new arenas. The wish to experiment with different formats was given free rein during the course of this project, enabling us to combine performance acts and performance lectures with workshops, presentations, films, exhibitions, discussions, seminars and walks.

In this article, I would like to reflect on certain parts of the walking project in order to investigate more closely how we transferred our experience as theatre practitioners to walking activities and, in doing so, activated imaginative attention in order to create observant moments in everyday situations.

\section{MAPPING THE FIELD OF WALKING}

The theme of walking is a somewhat rich one and can be looked at from a number of different angles. In the act of walking, there is an unfinished movement involved: someone is going somewhere. To walk is not only a matter of transporting oneself from one point to another, it may also facilitate and open up spaces for new thoughts, enable us to see life and existence from new places, encourage associative thinking, as well as help us go astray. It also opens up the way to metaphorical thinking. In Wanderlust: A History of Walking, author, historian and activist, Rebecca Solnit, has described walking and wandering as a deeply human activity in that it recreates a sense of connection, both to oneself and 
to the environment. ${ }^{1}$ In the corporeal understanding of what is happening in the outside world, there is imbedded information about the society and the political and social conditions that form our lives. ${ }^{2}$

In many ways, the cultural practice of walking has, historically, been a reaction against alienation and the fast pace of our industrialized world. In recent years, both activists and city planners have viewed walking as a subversive act that enables the transformation of order and power structures in society. "It may be countercultures and subcultures that will continue to walk in resistance to the postindustrial, postmodern loss of space, time, and embodiment," Solnit writes. ${ }^{3}$ Thus, one can consider walking as a way not only to create meaning, but also to initiate challenge and change. Moreover, it is also important to consider the ambiguous and open-ended character of walking. In an article in the book, The Ethics of Art: Ecological Turns in the Performing Arts, Christel Stalpaert and Karolien Byttebier state that, "walking artists celebrate the aimless movement of walking and the plentitude of meaning it provides space for". They discuss how walking might contribute with a gaze that is free from utilitarian associations and that the joy of walking is actually located in the diversity of meanings that the world gives evidence of. ${ }^{4}$

Walking As Art opened up as a field in the 1960s, when artists began to focus on the body, the process, and the presentation of action, rather than on the representation of objects as the artistic medium. The act of walking is considered a way to perceive, view and construct the world and, in recent years, walking has also begun to emerge as an interdisciplinary artistic, as well as theoretical, field in an international context. In a European context, and not least in the UK, walking has also been pointed to as being an important trend in the arts, where even performing artists have increasingly started to use the city as their stage.

What distinguishes pedestrian performance from many other art forms associated with walking, such as psychogeographical writing or a number of visual representations on the theme of walking, is its relation to time. Performance deals specifically with the live moment, as Carl Lavery writes in an article on the history, aesthetics and ethics of pedestrian performance in relation to his own Mourning Walk, and the objective of the pedestrian performance is to "overwhelm us in the present, to provide us with actual experience, to make the world 'float' in the here and now. This is where pedestrian performance displays its avant-garde heritage: its ultimate purpose is to replace vicarious experience (reading someone else's account of space) with actual experience (producing one's own spatial map)."5 This perspective was of significance in our project, too, both with regard to our theatre practice and to the fact that the audience actually shares the same space and time as the performers, which Lavery describes as a stimulus or a method "for encouraging spectators to rewrite and imagine their own city". ${ }^{6}$

In our project, we wanted to use physical acting techniques in order to create attention, "presentness" and meaning in situations that emerged in the streets. Our aim here was to go beyond the automatic patterns of the everyday when walking through town - an action that is so common in our habitual movement from one place to another - in order to activate a way to relate to the environment and to create experience (or "site") that develops both the attention and imagination of the one who walks. Our intention was to focus on the seemingly small and invisible stories and observations of the everyday, while actively carrying out a psychophysical walk. ${ }^{7}$

Streets in urban cities are, unfortunately, extremely underused for the most part. Neither are they valued as a city space for people to live in, but first and foremost as a transport route, where they are often the product of the City Traffic Planning Office's visions. Problems of this kind are discussed by architect Stefan Sjöberg in an article in the Swedish Architecture magazine, Arkitektur, where he pleads for city planners to show a greater interest in local contexts, what he calls the microplaces of the city (without, for that matter, turning the whole city into a "living room"). ${ }^{8}$ Lavery describes how citizens, as a consequence of contemporary urban planners having failed to create creative environments for people, have now started to search for alternative methods, which, in turn, involve imagining and poeticizing in an effort to counteract the poverty of their everyday surroundings. ${ }^{9}$ 
In our project, we chose to place our walks in the core of our everyday lives, in the neighbourhood where we lived or in the artist run studio area where our working space was situated, as well as along the different paths our everyday walking through the city took us. Some specific activities were also taking place at and around the World Culture Museum in Gothenburg. ${ }^{10}$ This meant that we mainly situated ourselves within the radius of the city centre. We used both street environments and more open spaces and sometimes even semi-naturescapes. Some of these locations can be considered rather dull and boring for pedestrians, whilst others seem more interesting. Our focus here, however, was mainly on the walker and his or her attitude and attention when encountering different environments (and "any place") with the purpose of creating meaning and new ways of perceiving in familiar situations.

The working title of the walking project was GångART $T^{11}$, which included a wide range of activ- ities and events, as well as several sub-projects. The different practices that emerged from GangART can be divided into our own explorative walks documented through "walking journals", participatory walks with others, performance acts that were presented to "involuntary" spectators and public presentations that included performance lectures, discussions and exhibitions. In most cases, these different activities were related and placed into one and the same framework.

From the beginning, it was clear that walking could, of course, be performed by employing different points of reference. I could for example choose to do my daily walk through my neighbourhood on my way to work with the aim of reaching my destination as quickly as possible (which I usually do), or to walk in order to think through a serious problem or a conflict with a friend, or I could also choose to do my walk as though it was a theatre act. How I do these different walks will, naturally, influence not

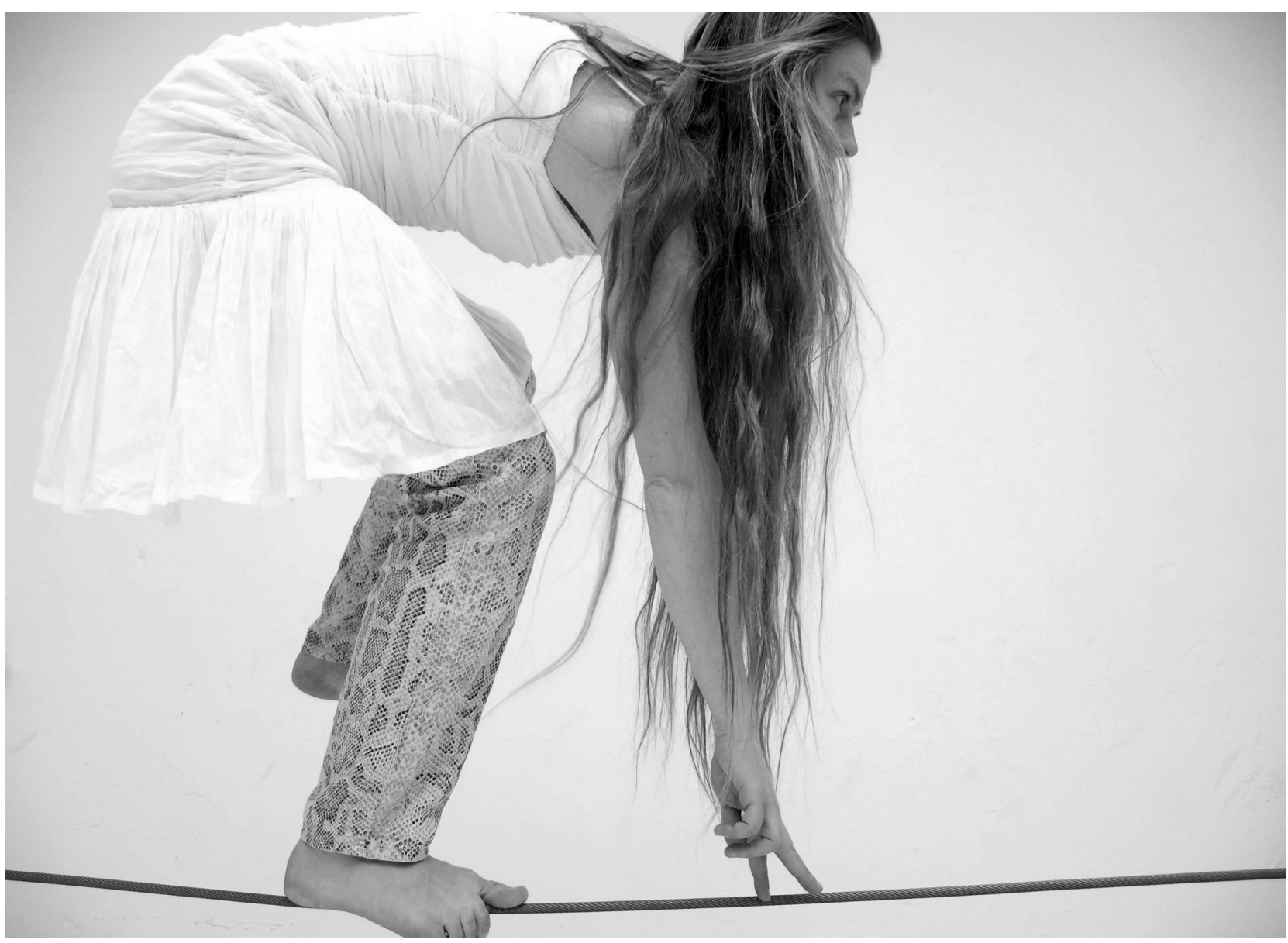

Fig. 1. Helena Kågemark in GångART. Photography: Imre Zsibrik. 
only the level of attention given to the act of walking, but also my perception of the surroundings and my way of thinking in the moment. I realized that when I performed my walk with reference to my experience from the theatre, there were specific patterns being activated in my walk, such as clear body awareness, more imaginative interpretations of the surroundings as well as a mobile and minimalist way of thinking. It was this kind of experience that we wanted to "play around with" in our walking project. However, in order to understand how our theatre work could be activated in a city context, and where our aim was to develop new experiences of the everyday beyond mere site-specific performances, we had to revisit our theatre work and the actor training we had once pursued.

\section{THEATRE WORK AS A WAY OF WALKING}

My working partner and I are both strongly influenced by the Swedish laboratory theatre group Institutet för Scenkonst (The Institute for Scenic Art). When we studied theatre with this group in the 1990s, we took part in both pedagogical and artistic work. Actor training at Institutet för Scenkonst was always closely connected to creative, artistic work, as well as to practical research, where the work that was carried out within the group was continually allowed to develop further on a continual basis. We have stayed in contact with Institutet för Scenkonst during the years that have passed and we are still influenced by its working principles, as well as its general approach to making theatre. ${ }^{12}$

Since the theatre work we pursue is usually based on improvisation and the gradual development of material during the course of longer sessions in a studio, the work undertaken is characterized by an uninterrupted flux. The actress is constantly on her way, from one point to another and many things may appear along her path. The action that occurs is a result of the instant choices the actress makes with regard to her physical actions and intentions, which, in turn, are shaped by the associations, impulses and memories that arise in the moment, as well as the compositional aspects that are involved with regard to space and dynamics and how these are used. Here, both familiar as well as unknown patterns emerge. It is indeed like treading a main road, sometimes alternating between going off into back roads and, at times, perhaps, going astray or

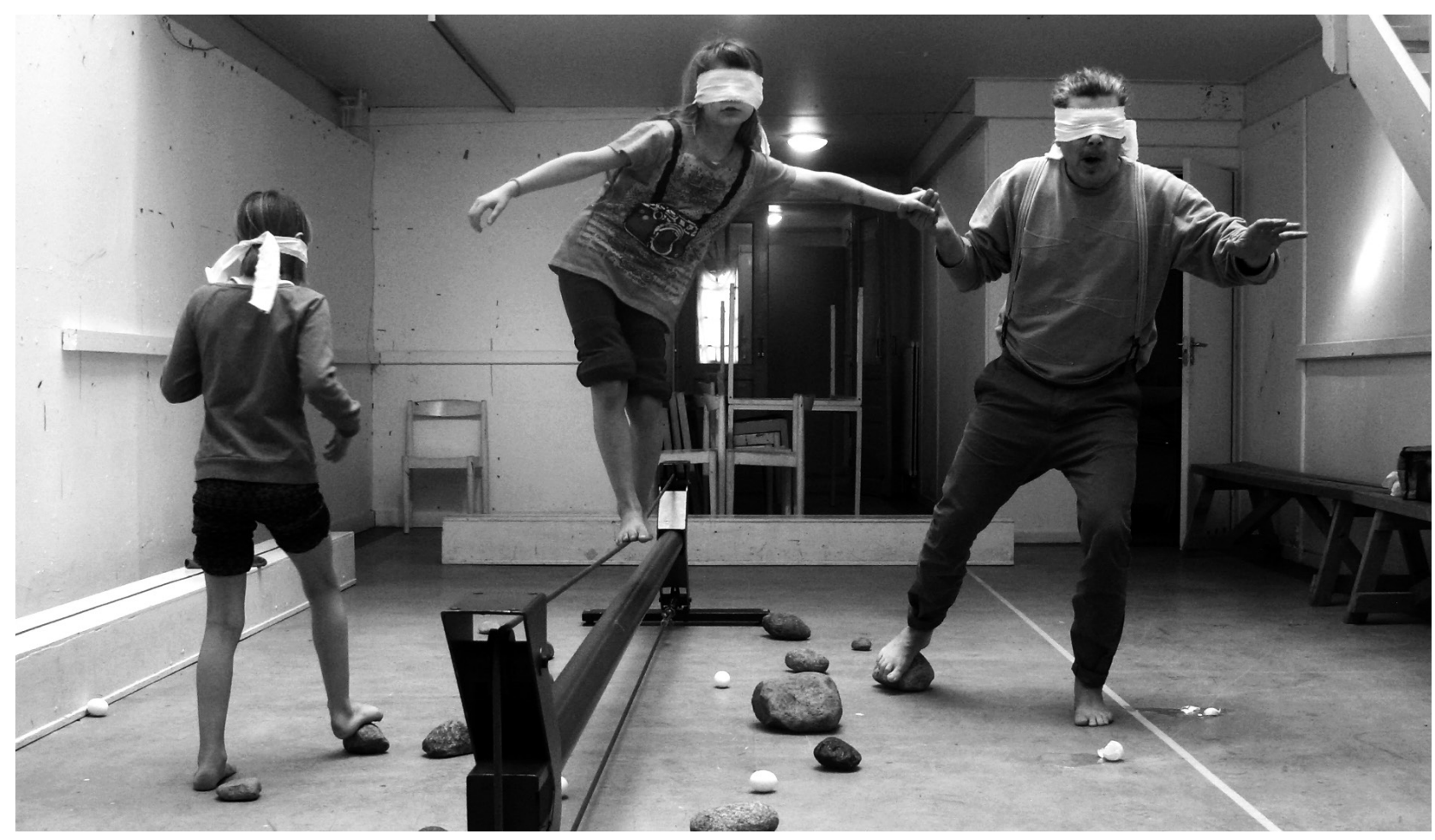

Fig. 2. Workshop activities at Konstepidemin (Epidemic Art Studios) in Gothenburg. Photography: Helena Kågemark. 
getting lost, and where the act of walking becomes a link between body and environment. This means that there is no absolute boundary between body and environment, between the mind and the physical; things are perceived by incorporating them into the body, but the body is also being perceived by turning to the things outside oneself, as thinker Michael Polanyi claims in his book The Tacit Dimension. ${ }^{13}$

In the actress's performance of concrete physical actions she projects herself in space. Every action takes shape with a certain dynamic, intention and direction (whether this is conscious or not). And the action is on its way somewhere. How these actions are to be composed, combined and contextualized is usually a question that arises later on in the process and they develop out of long-term collaborative work between actors and director (and perhaps other collaborators as well). What kind of signification the actions are to carry in relation to the performance created and the audience in question is thus something that is addressed in another phase of the work. ${ }^{14}$ For the actress, it is a matter of treading a path and letting relationships and situations arise. Encounters with co-actors, spectators and the surroundings will occur. To be able to meet others - and to create or identify social situations - is an advanced skill that actors adopt in improvisational work, where they neither force nor avoid possible meetings. Ingemar Lindh, the former leader of Institutet för Scenkonst, used to say that an actor has to be actively passive or passively active. This meant being completely relaxed but at the same time being totally ready to act, if needed - to be prepared. He compared this situation to how practitioners of martial arts do not act from personal emotions, needs or motives, but keep themselves open and responsive. This also relates to the so-called mutation work and the disinterested act, which are concepts coined through the research work conducted at Institutet för Scenkonst. Here, actors trained their ability to listen to the smallest changes in the ongoing, living process without, for that matter, intending to act, or to train their ability to act without any speculation or wish to steer a result. Lindh also talked about being sensitive to the "necessity of the moment". ${ }^{15}$

To act is to listen. It is about being able to read the consequences of one's action. How did my action reach out through the room? Which resonances did it cause? How did the surroundings respond? What is the next step? Listening, however, is also involved in shaping the action. The act of doing and that of listening are closely interconnected; they take place in micro-moments, more or less simultaneously. The action comes into being in a context that has already, from the beginning, been perceived by the one who acts. It is already a response to a situation, or a response to, or rather, a dialogue with the world.

The anthropologist Tim Ingold writes that, "the role of the artist is not to reproduce a preconceived idea, novel or not, but to join with and follow the forces and flows of material that bring the form of the work into being". ${ }^{16}$ With reference to Gilles Deleuze and Félix Guattari he underlines that improvisation is about following "the ways of the world, as they unfold rather than to connect up, in reverse, a series of points already traversed. It is 'to join with the World, or to meld with it'." ${ }^{17}$ This description corresponds well with the theatre work we pursue, where both the act of listening and that of following "the ways of the world" seem, in accordance with the former description, central in our practice.

\section{TAKING ONE STEP - THE ART OF LISTENING}

The second track we followed at the beginning of the project was the concept of walking. This began with an analysis of what it means physically to walk, to take a step. In ways to wander, an interdisciplinary catalogue of suggestions, instructions and activities for walking, we contributed with an instruction on the complexity of taking one single step: "While you empty your left leg, move your weight slowly over to your right leg. Investigate the structure of the soil. When all your weight is placed to the right of your body, carefully lift your left foot. Feel the heel off the ground, bringing the entire foot into the air. You float, you levitate above the ground. You struggle with balance and gravity. Rest assured that the ground will be there for you. You see far out over the landscape. Accept what has been and what is to come. Take a deep breath. It is time for a deci- 
sion, where will you put down your foot? Choose a spot carefully. Heel against the ground. A fall down forward." 18

We tried to deconstruct the action of taking one step. Where does it start? Which muscles are involved, where is the initiative and how does the action involve different parts of the body-mind? How does this act relate to the surroundings? We basically used the same approach as in our theatre work, activating an attentive quality that was both imaginative and psychophysical.

We went on walks in our neighbourhood and wrote notes afterwards in our walking journals. This meant collecting material and sub-themes, whilst exploring deeper into the act of walking. Usually we went on longer or shorter solitary walks in the city. During one specific period, we went on a daily route around the building where we have our studio in Gothenburg. These walks activated a reflection-in-action on different topics within the frame of walking and included topics such as women walking alone, getting lost, the right of public access or obstacles along the way. ${ }^{19}$

Observations from one walk: "The thing that catches my attention already at the beginning of the walk is all the fences and enclosures in different materials. Limits. There are remains of former borders or even current ones that do not need to be marked clearly. Others distinctly signal, in a "high tone of voice", that there is a barrier to keep out what is not wanted. I am passing several gates and doors that are not possible to open or close any more, since plants have twined their way around them and they have become stuck to the ground. Sometimes I think it's nice to have clear boundaries and markings that act as welcoming paths with their symbols and signs leading one gently forward. Even deviations and stops might also serve as clear and precise information." 20

Having gained experience from the walks, especially the short iterative routes around our studio building, we realized that it was the uniqueness of each walk, together with the observation of details, that constituted the focal point of our interest. We were looking for the small and often invisible stories of everyday life, those peripheral details that one does not often notice. We felt like "anthropologists of the near". ${ }^{21}$
The sociologist, Les Back, says that being able to listen to the world is not an automatic faculty, but a skill that has to be practised. ${ }^{22}$ Similar to the sociologist or the anthropologist, we were also studying the walks of everyday life, so to speak, and using different skills in order to listen to the world. Listening, in this context, means listening with all one's senses, which is a way of activating a democracy of the senses, as Les Back states. In the work of the sociologist it may be a matter of paying attention to the hidden life of objects and places, which is often concealed under the more spectacular events in life, or just neglected by power or forgetfulness. ${ }^{23}$

In our walks in the city, it was not only the observation of details that was important, but also, and not least, our way of interacting with the surroundings. We used our training from the theatre as a main reference, which in our act of walking meant activating bodily awareness, performing various actions (such as walking, stopping, turning and changing direction) and entering into the act of listening in and through the situation in order to see what would appear in the moment. We also applied a wide perception, reminiscent and close to the actor's way of keeping several different tracks open at one and the same time (that is, carrying out the planned action, adjusting to what is happening in the moment on stage, and being sensitive to the audience and the situation in the room). From an acting perspective, listening was not only a matter of taking in the environment, but meeting the environment by way of one's own act of walking through a site. The act of listening is, therefore, not only a matter of letting the surroundings in, but also entering spatiality. The French philosopher, Jean-Luc Nancy, comments on this in his beautiful little book on listening: "To listen is to enter that spatiality by which, at the same time, I am penetrated, for it opens up in me as well as around me, and from me as well as toward me: it opens me inside me as well as outside, and it is through such a double, quadruple, or sextuple opening that a 'self' can take place." 24

The subject in Nancy's world seems to dissolve in a number of ways and it is only by admitting a subject's indispensable relation to its surroundings "that a self can take place". In many ways, this resembles descriptions of the nomadic walker in the 
context of the theory of site-specific art, as someone always searching for mobile arrangements and who deterritorializes spaces. ${ }^{25}$ From a nomadic perspective, the environment, the outside, is a reversion or membrane of the inside, the world is a texture of the intimate. It is a de-individualized view of the subject. ${ }^{26}$

Similar to the way many sociologists view their work, it was not only a matter of describing, but also a matter of imagining and interpreting the surroundings. As in Clifford Geertz famous notion: thick description, imagination, creativity and selection are always involved when it comes to describing the world. ${ }^{27}$ When given time and space, we started to perceive details we had not seen before and we started to read familiar situations in new ways. We considered it poetry of everyday life and, in many ways, listening to the world could also be compared to the ways authors sometimes describe their writing as a process of listening for a story. It is a kind of imaginative attention that takes into consideration how the small details and events in a single story connect to larger sets of public issues. ${ }^{28}$

The writing connected to the walks, which was carried out immediately after each walk, became an important tool for us to grasp various perceptions on a number of different levels. The writing journals were simply descriptions of the walks and mapped its many layers through associations, memories, emotions, relations, and histories connected to the actual location and the walking. This relates to other scholars' way of regarding spatial practices as complex structures of life, where the individual walker creates different levels of narratives. ${ }^{29}$ Our writing journals relate both to autobiographic and ethnographic writing, which are two different notions that exist within the context of art walking. In line with the de-individualized subject discussed above, I would like to emphasize that our writing of journals did not only display a subject who "thinks", but also an environment that is made visible through a subject. This points to a more non-anthropocentric and environmental approach, where human participation in the world does not necessarily stand at the centre of things. The artist no longer has to be the origin and centre of artworks either, but is "rather someone who patiently responds to events in the surroundings", according to Lavery in his article on pedestrian performance. ${ }^{30}$

\section{WALKING AS A PROCESS OF NEGOTIATION}

In our project, the relation between art and non-art, between performance and participation, between performer and spectator is in many ways rather blurry. This is a common feature in many site-specific and walking projects. When something appears in a site, different sets of rules meet. In their influential book Theatre/Archeology, Mike Pearson and Michael Shanks point out three specific worlds that come together in the site-specific performance: the performance, the site and the audience. ${ }^{31}$ And these are constantly overlapping. Fiona Wilkie, who has written a number of important works on walking and performance, develops these thoughts further and highlights the aspect of negotiation as an aspect that is involved when different "worlds", or complex and overlapping sets of rules, meet. ${ }^{32}$ Site-specific performance is, in fact, a negotiation between different logics. When, for example, we presented the unannounced walking act Passing by outside the gigantic windows of the restaurant at the World Culture Museum in Gothenburg, the act was in many ways structured as a theatre piece. How the walk was to be performed and constructed included a clear beginning and end, a certain way of moving through space, a selected costume and a specific rhythm. Our intention here, was to create a contrast to the flow of fast-moving lunch guests at the restaurant, where the big windows were transformed into a scene or a screen, and became suddenly visible for those choosing to look. The site outside the window, with its grey rocks and stones in different sizes, created a suggestive ever-present back-drop for the walk that contrasted against the fleeting hustle and bustle of lunchtime inside the modern furnished restaurant, where lunch guests were, in turn, simultaneously exposed to a performance world.

In participatory walking events that are not framed as 'performances', but simply as walks in the city (even if they still can be read as performative events), a discussion on the different kinds of logics or frameworks that may be involved at a site becomes even more complicated. Is it at all possible to even 


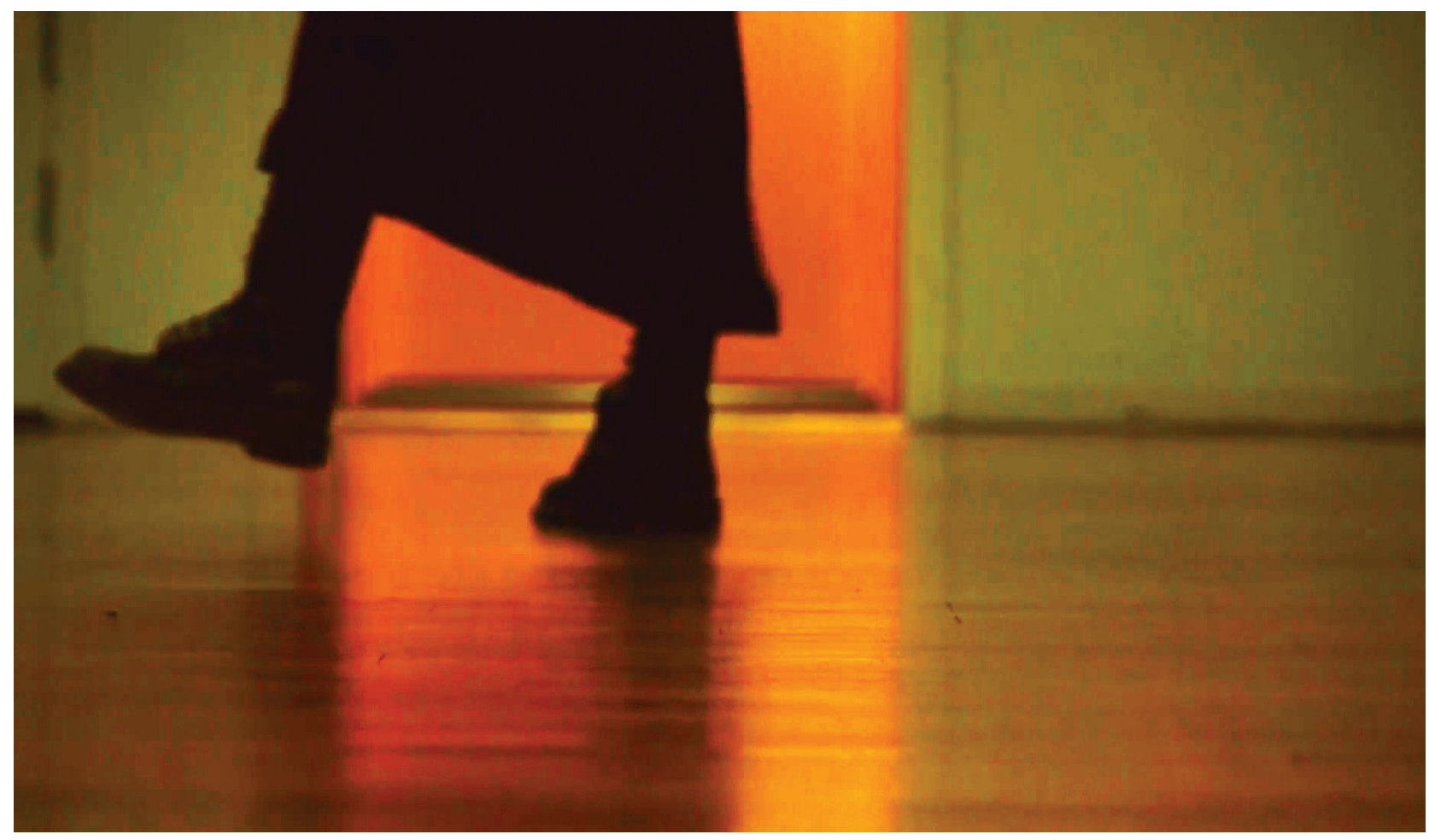

Fig. 3. A participant in our performance lecture at the World Culture Museum is exploring the act of taking a single step. Photography: Leo Palmestål.

distinguish between different frameworks? As many scholars have pointed out, a site is a result of what appears there and is constantly creating itself, which means it should not be possible to separate the location from its present constituent parts. ${ }^{33}$ Still, these constituent parts (the walker, other people present, the physical and social aspects of the location, for example) do, indeed, carry different sets of values and are in constant dialogue, or even friction, with each other, which makes the aspect of negotiation highly significant and valued. The participatory walks we conducted were not at all defined as "performance events" and usually not identified as such by passers-by either. Nevertheless, we put up frames for them, which were partly influenced by our "theatre logic". These included action-based instructions, a set timeframe for the activity, the handling of collective situations and that we were always present at the site. During the course of this process, we experienced that the act of negotiation between different sets of values was as prominent as ever when participants were moving through the site. By varying ways of responding to our set of rules for the walk and to the actual location in question, participants explored and processed such diverse phenomena as detours, micro ecosystems or memories of former lovers. ${ }^{34}$ In one of the notes, I wrote in my walking journal, I reflected upon the action of greeting people during a walk, which could be a further example of the constant process of negotiation that takes place between people in a site: "I choose to greet those I meet. Yesterday I did the opposite: was tired and introspective, but also wanted to see if others would greet me first. No one did. Today I choose to be the one who greets. When you meet a person in the woods, it feels natural and friendly to acknowledge the other person and say hello. I have learnt from my childhood that you greet people you meet, and in particular when out for a walk in the woods, in the countryside, and on lonely roads. I would like the world to be a place where one recognizes the other's presence. This doesn't mean that I say hello to a lonely man sitting on a bench, who chooses to turn away; I accept his wish. Nor does it mean that I say hello to joggers. I am walking in my universe and they in theirs, and, panting and puffing in their parallel universe, they are not available to meet me in mine. When I later come on to a larger walking 
trail I don't greet people anymore, since there is a steady stream of people all the time, and then it is no longer natural to say hello. We have now entered into the logic of the city." 35

The fluid way of moving about in the city that very much occupied our interest resembles the Situationists' well-known concept of drifting (dérive or psychogeography), a technique for exploring urban landscapes in order to analyse its impact on man and develop constructive strategies. ${ }^{36}$ In a dérive one or more persons go out in the city and let themselves be drawn by the attractions of the terrain and what they find there. The structures of the site influence the walker with its fixed points, enclosures and openings. In fact, the act of drifting was, in many ways, already compliant with our theatre work; we experienced our openness towards what was occurring in the moment, our attentiveness to the atmospheres and sensations that were generated in relation to the environment, and the de-stabilising aspect of drifting as familiar. Like the Situationists, we strived to find other ways of exploring than through producing art for consumption, even if we never totally left the art world in our project. In our case, we also only presented work where people did not have to pay to attend and where the emphasis was on participatory activities.

In spite of discovering that a number of aspects in our work were similar to the work of the Situationists, we did, however, realize that other structures were also being reproduced in the transference of our theatre work into our present process of drifting. These included: a certain organizing of space, our anchoring of the body, and the way we kept to given tasks and defined our walking in terms of physical actions, when moving ourselves through the city space. We discovered that frameworks emerged for the drifting activities we performed, which we both consciously and subconsciously, followed. We also realized that the theatre's demand for utility (economy of movements), precision (in choices and actions) and discipline (keeping deadlines and definied timetables) contrasted in an interesting way with the Situationists' wish to go beyond work ethics.

Our mapping activities, during the course of the walks we performed, eventually developed into a number of different walking instructions. These were structured as proposed walks in specific areas for others to take part in. We used many of the

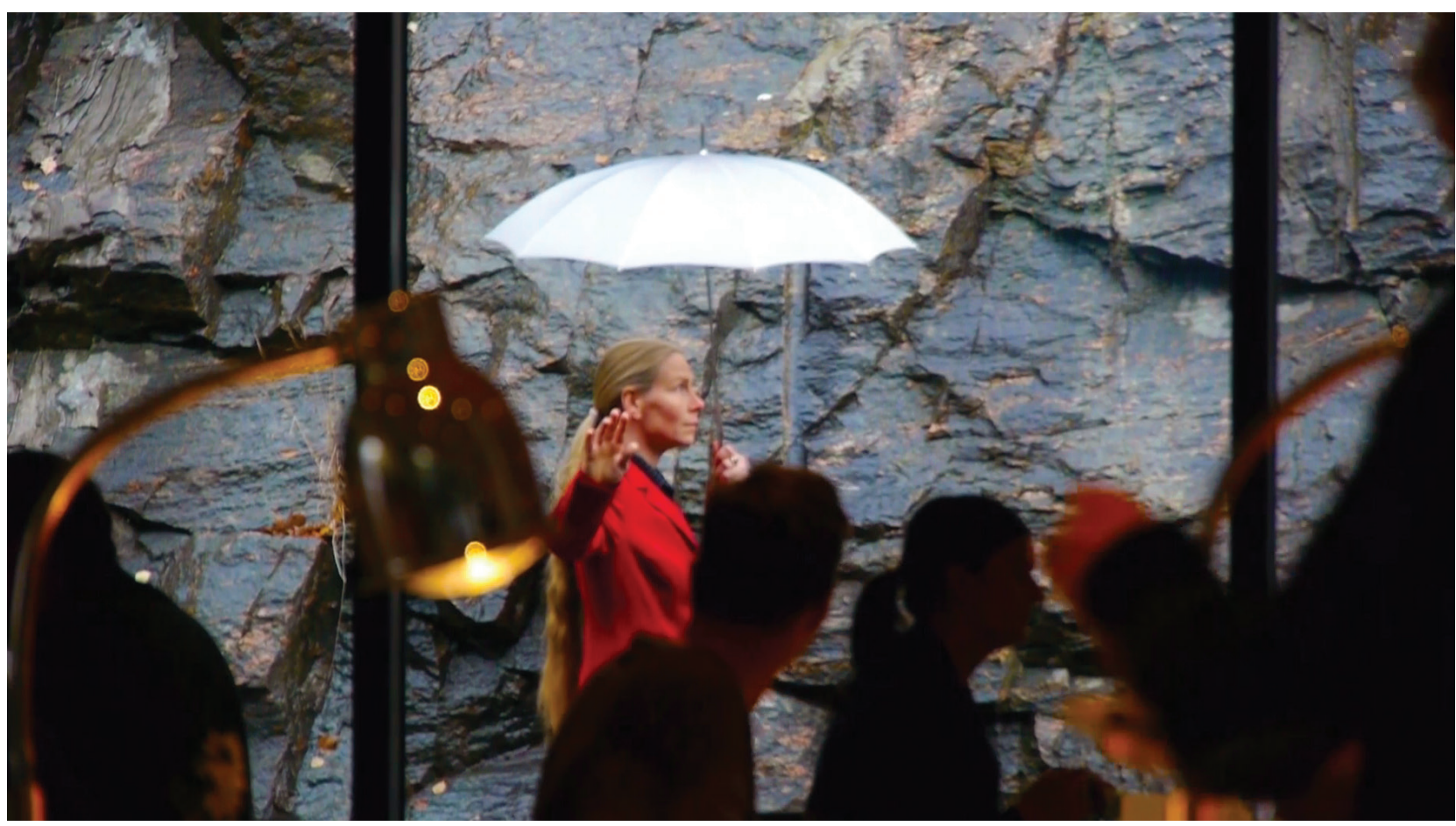

Fig. 4. Site-specific performance as a negotiation between different logics. Helena Kågemark in the performance act Passing by at the World Culture Museum in Gothenburg.

Photography: Leo Palmestål. 
themes we had been interested in and we also added subjective maps, inspired by other explorers using maps as subjective or emotional narratives (such as the Situationists, the eighteenth-century's Carte $d u$ Tendre or allegorical geographers). The walking instructions were examples of performative writing and shifted between description and instruction. They invited people to perform a walk that was both physical and imaginative, or "at the threshold between the physically experienced and the conceptually imagined; between what might be publicly witnessed and what is individually felt," as Emma Cocker expresses it from her own experiences from a walking project involving performative writing in the UK. ${ }^{37}$ Our instructions invited people to engage, without us being able to control any outcome. The instructions were handed out as "lunch walks" in one context, as Christmas gifts in another and exhibited in a gallery in a third. ${ }^{38}$ For us, it was an unfamiliar situation to invite people to a performance and then leave the scene, as we would not be able to experience what happened to our proposition, how and if people performed it and what they added to it. It was experienced as both a lack of feedback as well as a sense of freedom. We realized, ultimately, that the aspect of following-up is not always necessary or even wanted. A question that was constantly raised when working on the instructions, and something we took very seriously, addressed the balance between giving a clear frame for the proposition and leaving space for manoeuvre. Neither did we want to leave the participant without "flesh on the bones", nor eliminate the creative feeling of freedom and ownership. We also wanted the instructions to be both concrete and poetic, both open-ended and imaginative. We wanted them to operate between how things are and how they might be, not dissimilar to the magic if in the world of theatre, ${ }^{39}$ which involves activating an ability to see one thing as another.

\section{TO GET CLOSE AND TO MAKE STRANGE}

We realized that recognitions was an important aspect of our work. The artist Keri Smith's inspirational book How to Be an Explorer of the World gave further suggestions: "It is a known condition that when you begin to pay attention to something you've never really looked at before you will begin to see it everywhere." ${ }^{40}$ It is as though everything

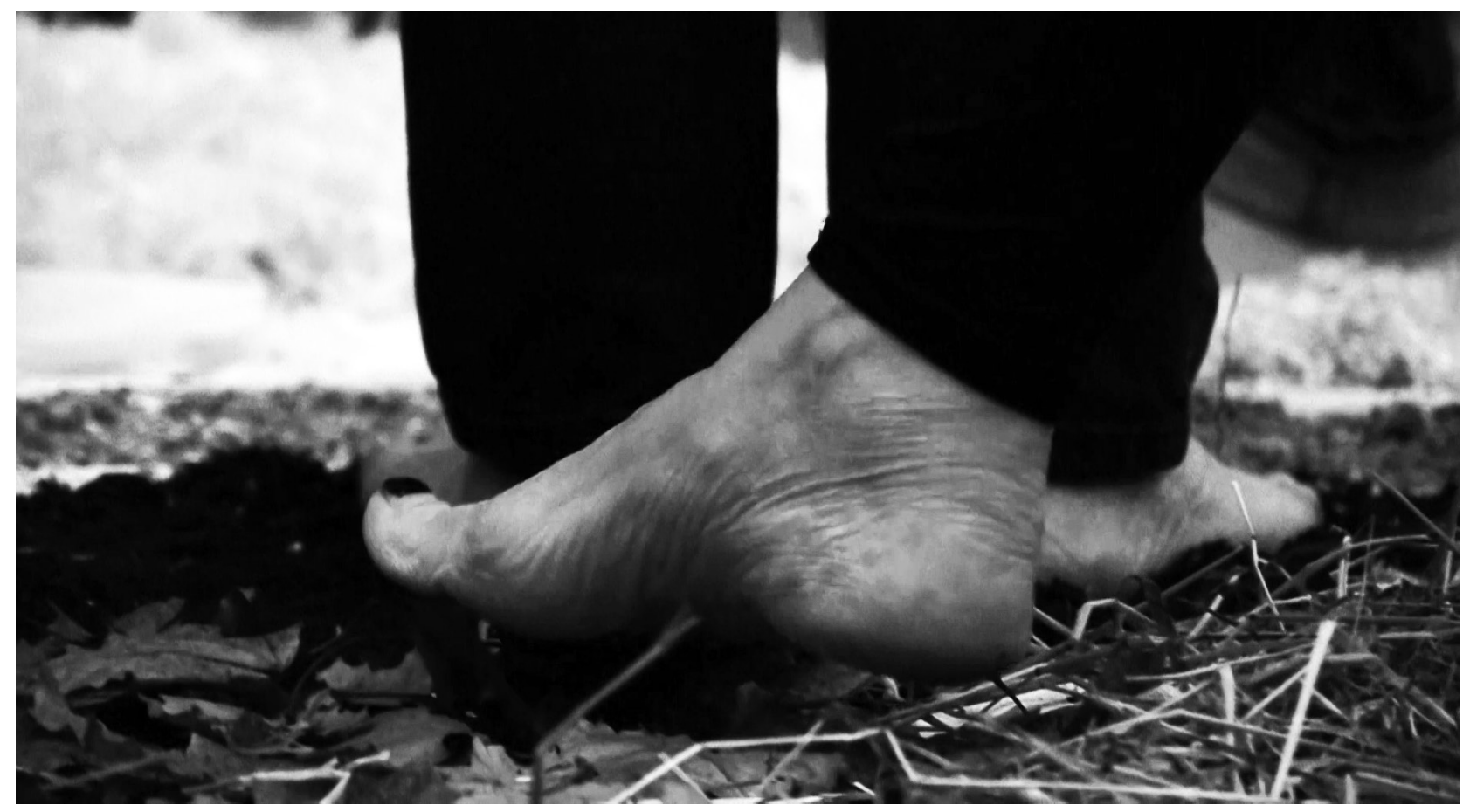

Fig. 5. Participants trying out different surfaces in the Barefoot Play Pen in our Walking Laboratory at the World Culture Museum. Photography: Leo Palmestål. 
revolves around your particular phenomenon. Or as Smith expressed: "You eventually begin to feel as if the thing is out to find you, instead of the other way around." ${ }^{11}$ The notion seems to have a magnetic force that attracts all kinds of things that come in its way. From this moment on, it creates recognitions, which drive the process forward. It is an important steering of the perception, which occurs in most artistic (and other) creative processes. ${ }^{42}$ In our theatre work recognitions were essential as a tool in the process of identifying material in improvisations or when working with details. In the process of exploring and developing theatrical material and practising meaning-making, crafting the same actions or details over and over again is an important part of the work. In this sense, recognition is a way of looking closer at something as well as expanding the perception of this something; however, it can also work as a means to distance or estrange.

In our Walking Laboratory at the World Culture Museum, one section was designed as a Barefoot Play Pen, where people could try out stepping on different surfaces, such as leaves, hay, soil, sawdust, feathers and damp sponges, sensing how it felt, smelt and sounded. Lifting materials or actions out of their ordinary contexts and placing them somewhere else, like in a section in a museum, signified, from our artist-researcher perspective, the creation of a lab situation. ${ }^{43}$ In this way, removing something from its ordinary situation or surroundings implies making it strange. It is about making us stop and see a familiar phenomenon or object with new eyes, as well as breaking automatic patterns and everyday monotony. In one of our walking instructions we focused on stone: "In front of you there is a stone area. Here you can see different types of stones: round ones, flat ones, small ones and big ones. Explore the material stone with the help of your feet and you stepping on them. Look around you with stone in mind. How much stone do you see in the surroundings? Associate on stone for a while. Where are you now?" 44

The Russian literary critic Victor Sklovskij talked about estrangement as an approach, that is, estrangement that aims at enhancing the difficulty and duration of perception. ${ }^{45}$ In this way, art could create resistance to the process of automatisation

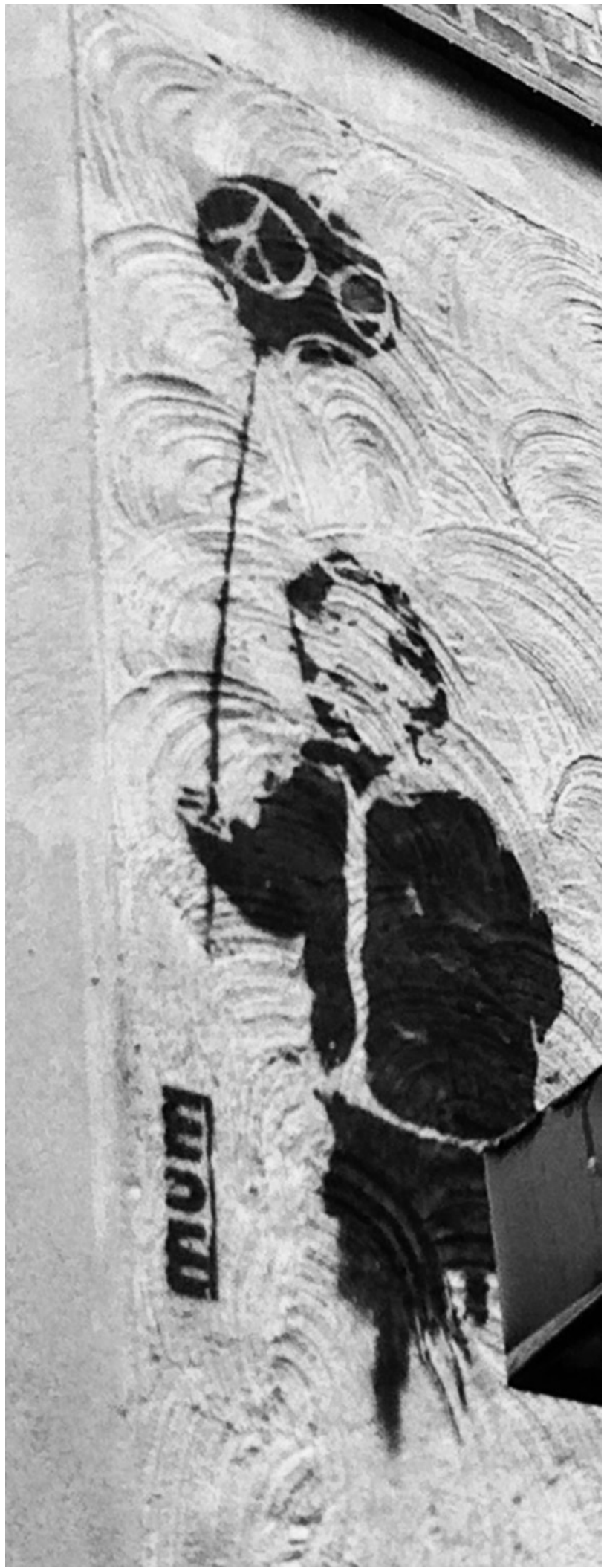

Fig. 6. Perceiving details and reading familiar sites in new ways. Wall painting in Gothenburg. Photography: Cecilia Lagerström. 
and in its place restore the sensation of life. In the world of the theatre, it was this aspect that Bertold Brecht, through his Verfremdungseffekt, developed further. ${ }^{46}$ It was a reaction against an attitude of general familiarity, or, as theorist Fredric Jameson puts it, against "a kind of perceptual numbness". ${ }^{47}$ Brecht believed that a representation that estranges is one that makes things seem unfamiliar, whilst, at the same time, making us recognize its subject.

The process of "making strange" was activated in our different activities: in the daily walks, in different experiments and in performative encounters with participant walkers. The "estrangement effect" implied seeing variations and new aspects of the familiar, whilst also sometimes being in situations of not recognizing and not knowing. In this sense, it was also a matter of going beyond the concept of the "magic if" and "seeing as", since if we are to be open for the unknown, "seeing as" could also mean that we miss out on "seeing more", when we already know what we are looking for.

We considered the moments of stopping to break the continuous flow in order to see something anew as observant moments. In these moments, there was usually a shift in perception, as well as a sense and experience of difference. Scholar Susan Haedicke discusses in the chapter of a book on public space and environmentalism how spectators may experience an experiential shock, when "onlookers, who see familiar sites through a lens of artistic imagination, experience a re-vision of what seemed established or permanent". ${ }^{48}$ She claims that it is this unexpected shift in the experience of what was, moments before, a familiar world, which causes this experiential shock. In my view, both the negotiation process and the clash between different frameworks or social discourses were key components in the creation of these observant moments when a shift of perception took place.

\section{WALKING ON}

As mentioned earlier, actor training is not only geared towards placing actions in a certain location, by the actor adopting a place, it is also a matter of allowing oneself to be affected by the surroundings. Not only in the streets are there items to relate to, but the latter also exist in a seemingly neutral studio space: the wooden floor, the air, which is never without substance, the sense of gravity when the body moves along the floor, the breath in one's nostrils, the warmth and heat of the room, the aesthetics of the studio interior, and the sounds leaking in from another room. There is nothing empty or neutral; there is sensory input in every space and situation. In our urban and non-urban walks, we adopted a listening approach where we permitted the location to "occupy" us, at the same time as we affected the surroundings. It was a way to generate the coming into being of a body-in-motion in co-creation with sites that were under constant construction, and in that movement relate actively passive or passively active, to refer back to Ingemar Lindh, in order to be attentive, responsive and open to that which we did not know beforehand.

The act of walking involves time and space: the bodily encounter with the world, the concrete conditions of matter and movement - all of these need time when part of a slow process. In today's society, this slowness and materiality sometimes deviate from the path of efficiency and rapid progress that characterizes the flickering flow of digital media and urban life. Here, of course, it must be noted that to be walking in a global mobile society with floating populations is very different from the society of the Cold War the Situationists performed their dérive in some decades ago. The Swedish poet, Sara Hallström, points out that walking in today's society might be a way of not disturbing the order in a place, showing that you are important, and, being afoot, have something to do. ${ }^{49}$ "It is almost only elderly people and children that are allowed to sit and linger in a place," she claims. So by exploring the act of walking in contemporary times, it becomes more and more apparent that there is as great a multiplicity of possible readings of the signification of this act as there is an abundance of ways to perform walking.

Walking is sometimes considered a "weak" activity, as it is process-based, participatory and unfinished. "Weakness legitimates uncertainty as a guiding factor, and privileges a concern for the small-scale over the large and the local over the global in relation to research across a variety of dis- 
ciplines", as Andrea Phillips points out in her article "cultural geographies in practice", which focuses on the relation between walking and looking. ${ }^{50}$ This position of weakness, of embedded experience rather than aesthetic representation, being focused upon is, at this moment in time, attracting a number of artists to want to explore the field of walking. Phillips notes that walking is, indeed, a movement that involves a criticism of representation, but that it constitutes, at the same time, a weak form of the latter.

While exploring the phenomenon of walking, we recognized aspects of our everyday lives that are easily forgotten or ignored and, seeing them anew, created observant moments. Here, it is a matter of recognising values in seemingly small, uninteresting details, gestures or stories; and to realize that what is significant is the way we approach, see and relate to these details and to the environment. In this way, it is possible for us to have an influence on the way we create environments and relations, as well as on the way we value and give meaning to things around us. This perspective is directly connected with the way we create theatre, that is, when we extract material from improvisations and explore details, actions and moments, and wait for the stories to emerge. The essential thing is to trust that there is something interesting to see and experience, and that both closeness (recognitions) and estrangement (distance), as well as imaginative attention and constant negotiations, are important tools.

In our project the boundaries between participating and spectating were often dissolved. The act of walking meant both performing and, simultaneously, viewing the world, and the mobile, open-ended and listening approach adopted in our work activates a constant process of searching for and negotiating meaning and form. Messages, interpretations and significations are never fixed, but are temporary. In that sense walking might be considered a weak activity, but it could also be seen as a way to undo dominant representations, preconceived ideas and static authorities, in line with thinkers of nomadic theory. ${ }^{51}$ It is the subversion of set conventions that defines the nomadic state and this opens up a space for new experiences in situations of the everyday.

Proof-reader: Lynn Preston Odengård

Digital image processing: Lars Bonde

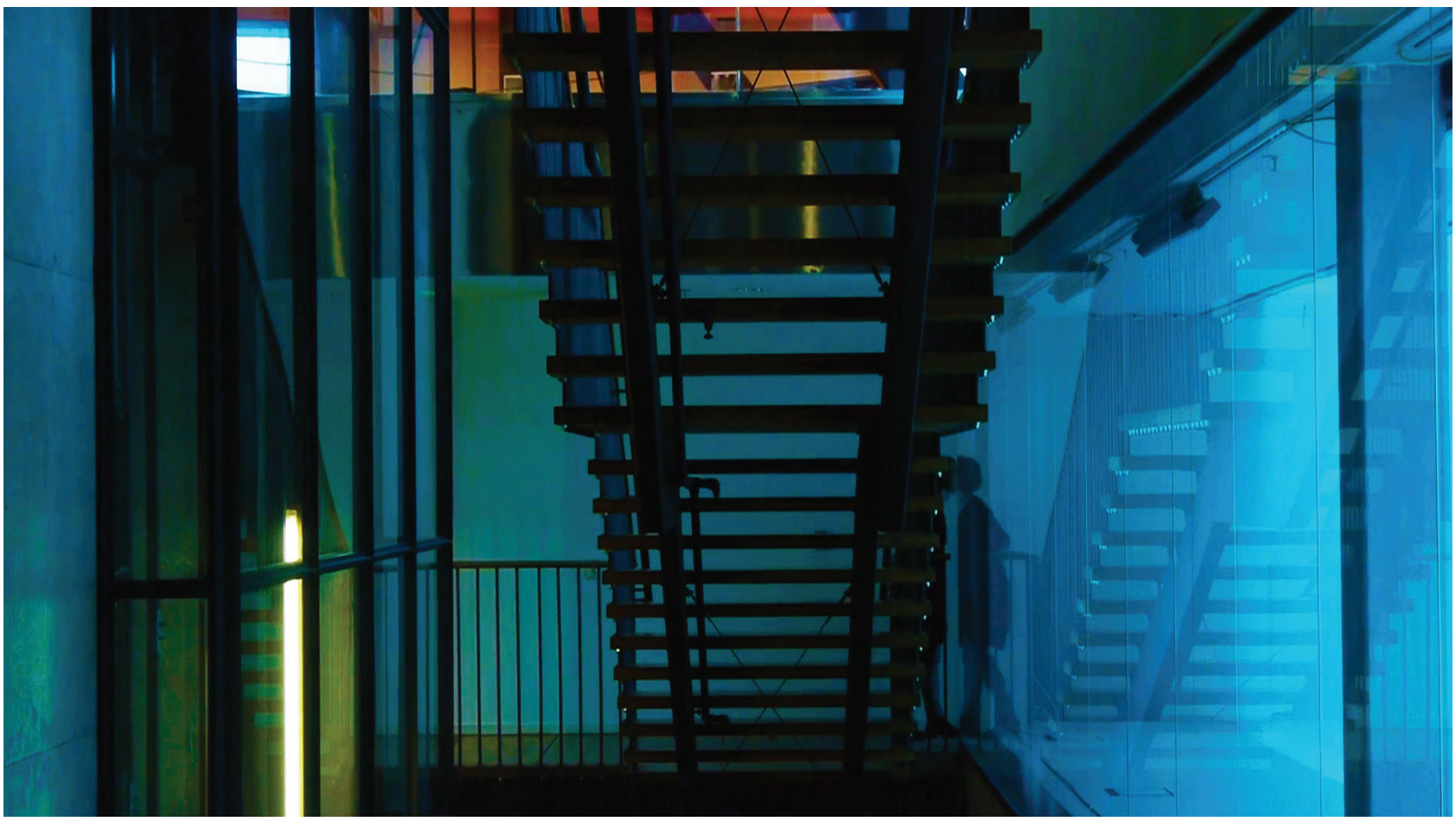

Fig. 7. Seeing sites through a lens of artistic imagination: revising what seemed permanent. A participating walker is looking through the interior glass walls at the World Culture Museum. Photography: Leo Palmestål. 


\section{NOTES AND REFERENCES}

1 Rebecca Solnit, Wanderlust: A History of Walking, Verso, London 2002.

2 This refers to Judith Butler's work, see Bodies That Matter: On the Discursive Limits of "sex", Routledge, New York 1993.

3 Solnit, op. cit., p. 267.

4 Christel Stalpaert, Karolien Byttebier, "Art and Ecology, Scenes from a Tumultuous Affair" in The Ethics of Art: Ecological Turns in the Performing Arts, Guy Cools, Pascal Gielen, eds., Antennae, Valiz, Amsterdam 2014, p. 75.

5 Carl Lavery, "Mourning Walk and Pedestrian Performance: History, Aesthetics and Ethics" in Walking, Writing \& Performance, Roberta Mock, ed., Intellect Books, Bristol 2009, p. 45.

6 Ibid.

7 The term is taken from Phillip Zarrilli who proposes a "psychophysical" understanding and approach to acting, with a working model which is not based on acting as representation but on an "energetics" of performance. (Zarilli draws on Stanislavski's use of the term in the nineteenth century). (Phillip B. Zarrilli, Psychophysical Acting: An Intercultural Approach after Stanislavski, Routledge, London, New York 2009.)

8 Stefan Sjöberg, "Gatan är stadens viktigaste plats" in $A r$ kitektur, No. 4, 2015.

9 Lavery, op. cit.

10 We had a residency week at the museum during 20-26 October 2014 with our project GångART.

11 A Swedish word meaning gait, but also referring to walk and art.

12 Institutet för Scenkonst was formed by Ingemar Lindh in Sweden in 1971, and he was the artistic leader of the group until he passed away in 1997. Since then, Institutet för Scenkonst is run by Lindh's close collaborators Magdalena Pietruska and Roger Rolin. Helena Kågemark has worked actively with the group during recent years, for example in the research work connected to the $\mathrm{X}$-project and the performance Imagine.

13 Michael Polanyi, The Tacit Dimension, University of Chicago Press, Chicago 1966.

14 The Institute calls this aspect of the work the difference between sense and signification.

15 The concepts coined by Institutet för Scenkonst are further developed in Lindh's book Stepping Stones (with an introduction by Frank Camillieri), Routledge, Oxford, New York 2013; in my own dissertation Forms for Life and Theatre: Institutet för Scenkonst and Tacit Knowing, Gidlunds, Hedemora 2003 and in Frank Cammillieri's articles about the group, for example in TDR.

16 Tim Ingold, "Bringing Things to Life: Creative Entanglements in a World of Materials”, Working paper \#15, University of Aberdeen, July 2010, p. 10.

17 Ibid.

18 Cecilia Lagerström, Helena Kågemark, "In One Step” in ways to wander, Clare Qualmann, Claire Hind, eds., Triarchy Press, Axminster 2015. The quote in the text is an excerpt from the instruction. This performative deconstruction was also transformed into a workshop activity and a performative event, making participants reflect, in action, on the act of walking.

19 Reflection-in-action is a concept coined by Donald Schön. See The Reflective Practitioner. How Professionals Think In Action, Arena, Aldershot 1995.

20 Helena Kågemark, Walking Journal, 7 May 2013, Vezzano Alto, Italy (my translation from Swedish).

21 A term relating to anthropology that explores everyday life in familiar situations rather than exotic cultures far away.

22 Les Back, The Art of Listening, Berg, Oxford, New York 2007.

23 Ibid.

24 Jean-Luc Nancy, Listening, transl. Charlotte Mandell, Fordham University Press, New York 2007, p. 14.

25 See for example Mike Pearson, Michael Shanks, Theatrel Archaeology, Routledge, London, New York 2001.

26 Elizabeth Adams St.Pierre, "Circling the Text. Nomadic Writing Practices" in Qualitative Inquiry, Vol. 3, No. 4, 1997, pp. 403-17.

27 Clifford Geertz, The Interpretation of Cultures: Selected Essays, Basic Books, New York 1973.

28 Back, op. cit.

29 For example, Michael de Certeau, perhaps the most cited in this area. See The Practice of Everyday Life, transl. Steven Rendall, University of California Press, Berkeley 2011.

30 Lavery, op. cit., p. 244.

31 Pearson, Shanks, op. cit.

32 Fiona Wilkie, "Kinds of Place at Bore Place: Site-Specific Performance and the Rules of Spatial Behaviour" in New Theatre Quarterly, Vol. 18, Issue 03, 2002, pp. 243-60.

33 See for example Sophie Nield, "Siting the People: Power, Protest, and Public Space" in Performing Site-Specific Theatre. Politics, Place, Practice, Anna Birch, Joanne Tomp- 
kins, eds., Palgrave Macmillan, Houndsmills 2012.

34 The organized collective walks we did were followed up by way of discussions and by people writing and drawing their subjective maps for us.

35 Cecilia Lagerström, Walking Journal, 29 September 2013, the woods around the Botanical Gardens in Gothenburg, Sweden (my translation from Swedish).

36 The Situationists originated in the Letterist International of the 1940s. See Guy Debord, "Introduction to a Critique of Urban Geography" in Situationists International Online, http://www.cddc.vt.edu/sionline/presitu/ geography.html, and several articles in Guy Debord and the Situationist International, Texts and Documents, Tom McDonough, ed., MIT Press, Cambridge 2002.

37 Emma Cocker, "Choreographing Collectivity through Invitation and Response" in Rhizomes, Issue 21, Winter 2010, p. 6.

38 With titles such as Walk in the Vague Terrain, Walk on Stone, Conversational Walk, Walk at The Crossroad, Walk around the Christmas Tree and Walk in One Step.

39 The magic if is a famous concept by theatre maker Konstantin Stanislavski, who still influences many theatre schools in the world. The actor uses it when creating a role character, asking her/himself what s/he would do, if s/he finds her/himself in the situation of the role; "as if...”. Here, I play around with the concept and use it in a more methaphorical way, meaning "seeing one thing as another" or seeing a familiar situation in another way.

40 Keri Smith, How to Be an Explorer of the World. Portable Art Life? Museum, Penguin Books, London 2008, p. 45.

41 Ibid.

42 The aspect of recognitions in creative processes is discussed in Barbro Smeds, "Skakande situationer - en resa i identitet och igenkänning" (Jolting Situations - A Journey in Identity and Recognition) in Berättelse och kunskap. Slutrapport nr 2 frän Kollegiet för forskning och utvecklingsarbete på det konstnärliga området, Dramatiska Institutet, Stockholm 2006, p. 159.

43 At the museum, we had to approach totally new requests when organizing the space we were to use there. All the organic material we brought into the building had to be frozen to -30 degrees in big freezers in the cellar of the museum. This underlined even more the separating of material from its surroundings in a process of making strange.

44 Cecilia Lagerström, Helena Kågemark, taken from the Lunch Walk No. 3: Walk on Stone, The World Culture
Museum in Gothenburg 2014.

45 Form och struktur. Texter till en metodologisk tradition inom litteraturvetenskapen, Kurt Aspelin, Bengt A. Lundberg, eds., Norstedt, Stockholm 1971.

46 Bertolt Brecht, Brecht on Theatre: The Development of an Aesthetic, John Willett, ed. and trasl., Methuen, London 1964.

47 Frederic Jameson, Brecht and Method, Verso, London, New York 1998.

48 Susan Haedicke, "Beyond Site-Specificity: Environmental Heterocosms on the Street" in Performing Site-Specific Theatre, op. cit., p. 103.

49 Sara Hallström, from the panel discussion at the event "Writing in the Moment" as part of the GangART programme at the World Culture Museum, 22 October 2014.

50 Andrea Phillips, "cultural geographies in practice: Walking and looking" in Cultural Geographies, Vol. 12, October 2005, p. 510 .

51 Rosi Braidotti, Nomadic Theory. The Portable Rosi Braidotti, Columbia University Press, New York 2011. 